07,13

\title{
Чувствительность дислокационных розеток к форме индентора Берковича на кристаллах LiF и MgO
}

\author{
(ㄷ Д. Грабко, К. Пырцак, О. Шикимака \\ Институт прикладной фризики, \\ Кишинев, Молдова \\ E-mail: grabco@mail.ru
}

Поступила в Редакцию 14 января 2020 г.

В окончательной редакции 17 февраля 2020 г.

Принята к печати 25 фревраля 2020 г.

\begin{abstract}
Рассматривается своеобразный эффект, наблюдаемый при индентировании грани (001) монокристаллов $\mathrm{LiF}$ и $\mathrm{MgO}$, а именно чувствительность вида дислокационных розеток к форме индентора. Показано, что дислокационные розетки, формирующиеся вокруг отпечатков Виккерса, имеют симметричный вид, тогда как розетки вокруг отпечатков Берковича ассимметричны, краевые лучи дислокационных розеток различаются по своей длине, а винтовые лучи такой асимметрии не демонстрируют. Также обнаружен ориентационный эффект при внедрении индентора Берковича: вид дислокационных розеток и длина краевых лучей меняются при изменении ориентации индентора относительно кристаллографических направлений образца. Показано также, что асимметрия дислокационных розеток проявляется ярче на более твердых кристаллах и увеличивается с ростом нагрузки на индентор. Установлены факторы, ответственные за аномалию в развитии дислокационных розеток при нано-, микроиндентировании индентором Берковича грани (001) кубических кристаллов.
\end{abstract}

Ключевые слова: монокристаллы $\mathrm{LiF}$ и $\mathrm{MgO}$, нано- и микроиндентирование, пирамиды Берковича и Виккерса, дислокационные розетки.

DOI: $10.21883 /$ FTT.2020.08.49607.003

\section{1. Введение}

Механизм деформации материалов при индентировании интенсивно исследуется в научной литературе на протяжении уже нескольких десятилетий [1-17]. Во-первых, это связано с тем, что метод индентирования приобрел характер универсального способа для оценки механических свойств различных материалов: твердости, прочности, упругости, пластичности, хрупкости $[3,4,18,19]$. Во-вторых, для определения этих свойств применяются различные методы измерения твердости (макроиндентирование, инденторы Бринеля и Роквелла, микроиндентирование (МИ), инденторы Виккерса и Кнупа, наноиндентирование (НИ), индентор Берковича), совершая качественный переход к новому, более высокому классу точности определения этой важной прочностной характеристики материалов. Метод инструментального (глубинно-чувствительного) наноиндентирования занял лидирующее положение среди всех остальных методов определения механических свойств материалов, поскольку позволяет определять как твердость, модуль Юнга, так и несколько десятков других функциональных характеристик материалов.

Метод НИ реализуется путем приложения к испытуемому образцу сосредоточенной нагрузки с помощью индентора и автоматизированного измерения деформации материала с точностью порядка десятых долей нанометров. Метод НИ может применяться для определения механических свойств практически любых материалов (объемных и наноразмерных образцов, многослойных структур, тонких пленок на различных подложках и др.) [2-10,18-27]. С его помощью исследуются ионные и ковалентные монокристаллы $(\mathrm{KCl}, \mathrm{LiF}, \mathrm{Si}$, InP) $[2,4-7,9,10,21]$, металлы $(\mathrm{Al}, \mathrm{Cu}, \mathrm{W})[18,19]$, оксиды $\left(\mathrm{ZnO}, \mathrm{MgO}, \mathrm{SiO}_{2}, \mathrm{Al}_{2} \mathrm{O}_{3}, \mathrm{~B}_{6} \mathrm{O}, \mathrm{SrTiO}_{3}\right)$ [19,24], твердые и свехтвердые соединения [19], молекулярные кристаллы [25], тонкие пленки [23], полимеры [26], стекла [27] и др. Этот небольшой перечень материалов, исследуемых с помощью наноиндентирования, наглядно демонстрирует степень его применения специалистами, занимающихся вопросами физики прочности и пластичности и физического материаловедения. Однако столь широкое использование метода НИ предполагает, прежде всего, понимание специфики метода, корректную интерпретацию получаемых результатов и знание основных закономерностей протекания процесса индентирования.

Необходимость правильного, грамотного использования новых методов требует проведения новых научных изысканий, с целью проникновения в природу явлений, сопровождающих процесс индентирования, и расширения представлений о свойствах материалов в микрообъемах и нанообъемах.

К настоящему времени накоплен огромный экспериментальный материал в плане выяснения физики процесса микроиндентирования $[1,4,6,7,9,10]$. Установлены многие закономерности деформации и разрушения ионных и ковалентных кристаллов, построены модели пластического течения материала при микровдавлива- 
нии $[1,4,6,28,29]$. Определено, что процессом пластического деформирования кристаллов управляют два основных фактора: напряженное состояние, возникающее в кристалле при действии сосредоточенной силы [30], и геометрия скольжения, зависящая от особенностей кристаллической структуры исследуемого вещества $[2,4,29]$.

Степень вклада одного или другого фактора определяется конкретными условиями испытания (температурой, предварительной обработкой образца, условиями нагружения и др.). Установлено, что независимо от структуры кристаллов и типа химической связи в них, деформированная зона отпечатка в общем случае состоит из пяти областей, которые характеризуются различной степенью пластической деформации: 1 - супердефектная зона, самая близкая к отпечатку, 2 - деструктурированная область, 3 - область с высокой плотностью дислокаций, 4 - периферическая дислокационная область, 5 область упругой деформации [6]. Важно отметить, что одновременно все участки реализуются лишь в средней относительной области температур $T_{a v} \sim(0.5-2.0) \Theta_{\mathrm{D}}$ (где $\Theta_{\mathrm{D}}-$ температура Дебая). В области температур $T<T_{a v}$ менее развиты или отсутствуют области 3 и 4; при $T>T_{a v}$ почти не формируются области 1 и 2 . Эти и многие другие результаты в совокупности позволили установить общие закономерности деформирования при микроиндентировании и выявить основные факторы, определяющие процесс образования отпечатка.

В то же время было показано, что процесс индентирования характеризуется и некоторыми специфическими закономерностями, которые проявляются при изменении ориентации индентора относительно кристаллографических направлений образца или при использовании инденторов различной формы, например, пирамиды Виккерса и пирамиды Кнупа $[1,4]$. Так, для кристаллов со структурой типа $\mathrm{NaCl}$ выявлена анизотропия микротвердости для двух ориентаций индентора: $H_{d \|\langle 100\rangle}>H_{d \|\langle 110\rangle}$ $(d-$ диагональ отпечатка). Для серии ионных и ионноковалентных кристаллов обнаружен ориентационный эффект, изменение длины дислокационных лучей розеток при изменении ориентации индентора $(d \|\langle 100\rangle$ и $d \|\langle 110\rangle)[4,31]$.

Однако, по-прежнему, сохраняются многие вопросы, требующие решения. Эти проблемы оказываются в значительной степени нерешенными при переходе от микроиндентирования к наноиндентированию, тем более, что для измерения твердости этими двумя методами применяются инденторы различной формы: четырехгранная алмазная пирамида Виккерса для МИ и трехгранная алмазная пирамида Берковича для НИ. Возникает вопрос, сохраняется ли форма детально исследованных в научной литературе дислокационных структур вокруг отпечатков при переходе от пирамиды Виккерса к пирамиде Берковича. В связи с этим в настоящей работе проведено исследование вида и специфики образования дислокационных структур вокруг отпечатков в случае квазистатического микроиндентирования (индентор пи- рамида Виккерса) и инструментального микро- и наноиндентирования (индентор пирамида Берковича).

\section{2. Материал и методика проведения эксперимента}

Для изучения поставленной задачи была выбраны ионные монокристаллы $\mathrm{LiF}$ и ионно-ковалентные $\mathrm{MgO}$, грань (001). Выбор этих кристаллов для изучения вида дислокационных структур был сделан на основании того, что для них детально изучено распределение дислокаций в окрестности отпечатков, известны элементы скольжения и спайности, построены схемы пластического течения материала при микроиндентировании, что будет способствовать лучшему пониманию процессов, протекающих при микро- и наноиндентировании. Монокристаллы $\mathrm{LiF}$ и $\mathrm{MgO}$ обладают кубической структурой типа $\mathrm{NaCl}$ с элементами скольжения $\{110\}\langle 110\rangle$. Их микротвердость соответственно равна $H_{B} \approx 1.1 \mathrm{GPa}$ для $\mathrm{LiF}$ и $H_{B} \approx 8.0 \mathrm{GPa}$ для $\mathrm{MgO}$.

Изучение механических свойств проводили квазистатическим методом на микротвердомере ПМТ-3, оснащенном индентором Виккерса и методом инструментального (глубинно-чувствительного) индентирования на приборе Nanotester-PMT-NI-02, оснащенном индентором Берковича. Диагонали отпечатков Виккерса были ориентированы по направлениям $\langle 100\rangle$, стороны отпечатков при этом были направлены вдоль $\langle 110\rangle$. Отпечатки Берковича были нанесены при двух ориентациях: 1 - одна из трех сторон параллельна направлению $\langle 110\rangle$, и $2-$ одна из трех сторон параллельна направлению $\langle 100\rangle$. Микроструктура поверхности изучалась методом оптической микроскопии $(\mathrm{OM})$ на приборах XJL-101 и Amplival с цифровым мониторингом и атомно-силовой микроскопии (ACM) на приборе AFM Nanostation II. Следует указать, что в литературе, как правило, изучается нано- и микрорельеф поверхности около отпечатков и гораздо меньше исследуется механизм деформирования на дислокационном уровне, хотя именно сочетание различных методов исследования позволяет получить наиболее объективную информацию относительно процессов, протекающих в материалах на микро- и наноуровне [32]. С учетом сказанного, вышеуказанные методы были дополнены методом химического травления для выявления дислокационных структур вокруг отпечатков. Метод химического травления - это простой, наглядный и информативный метод, позволяющий визуализировать специфику образования дислокационных розеток в окрестности отпечатков индентора для широкого интервала нагрузок.

Для выявления дислокационных структур на кристаллах $\mathrm{LiF}$ использовался стандартный селективный травитель: слабо концентрированный водный раствор $\mathrm{FeCl}_{3}$ (время травления $\sim 1 \mathrm{~min}$ ), а для кристаллов $\mathrm{MgO}$ раствор $5 \cdot \mathrm{NH}_{4} \mathrm{Cl}+1 \cdot \mathrm{H}_{2} \mathrm{O}+1 \cdot \mathrm{H}_{2} \mathrm{SO}_{4}$ (время травления $\sim 15 \mathrm{~min})$. 


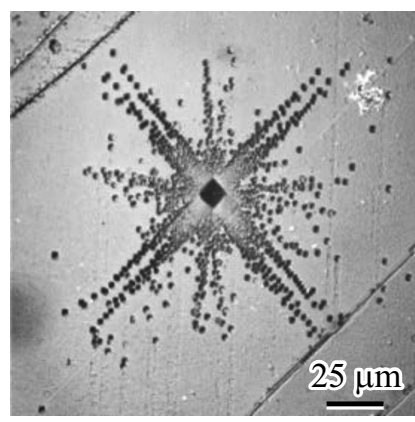

e

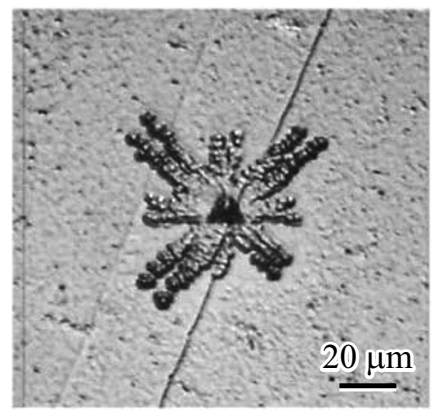

$b$

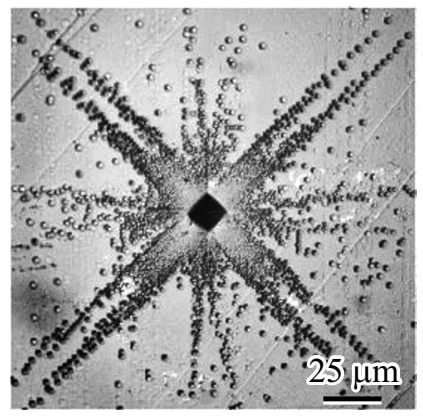

$f$

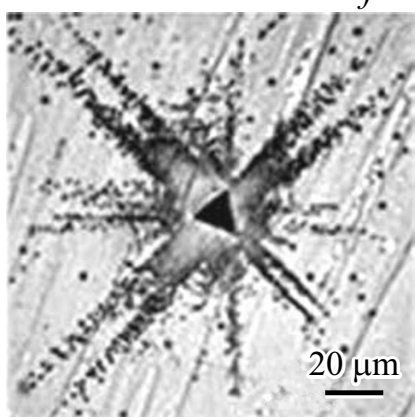

$c$
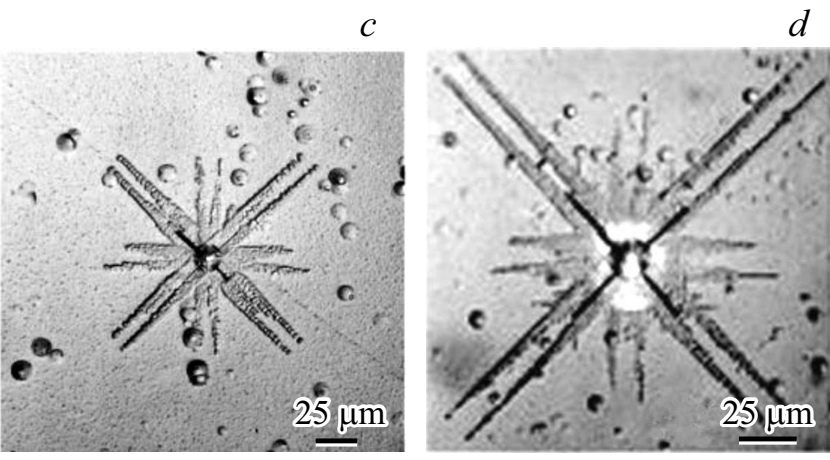

$g$

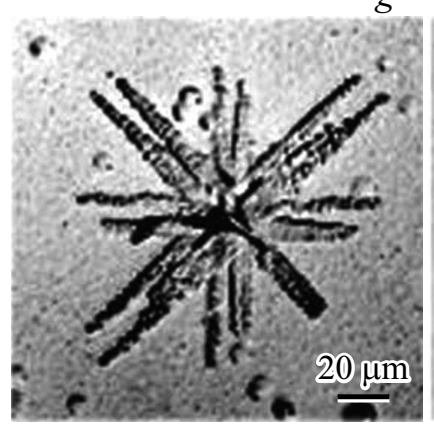

$h$

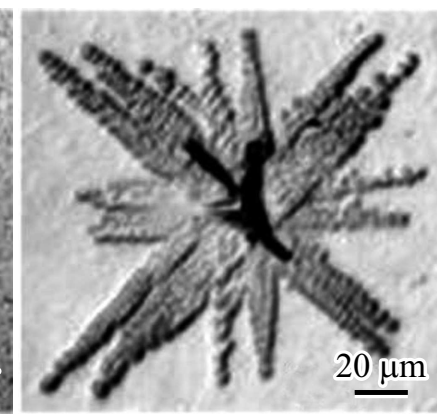

Рис. 1. Вид дислокационных розеткок, образующихся вокруг отпечатков индентора Виккерса $(a-d)$ и индентора Берковича $(e-h)$ на грани (001) монокристаллов $\operatorname{LiF}(a, b, e, f)$ и $\mathrm{MgO}(c, d, g, h) . P, \mathrm{mN}: a, e-100, b, f-500, c, g-300, d-1000, h-700$.

\section{3. Результаты и обсуждение}

Изучение дислокационных структур, формирующихся вокруг отпечатков инденторов Виккерса и Берковича, выявило примечательный эффект, а именно чувствительность вида дислокационных розеток к форме индентора. Обратимся к рис. 1. На нем представлены дислокационные розетки вокруг отпечатков, нанесенных индентором Виккерса (рис. 1, $a-d$ ) и индентором Берковича (рис. $1, e-h)$ на грань (001) монокристаллов $\mathrm{LiF}$ (рис. $1, a, b, e, f)$ и $\mathrm{MgO}$ (рис. $1, c, d, g, h)$.

В первую очередь отметим те особенности, которые характерны для розеток обоего типа. В общих чертах дислокационные розетки похожи между собой. Каждая розетка сформирована из восьми дислокационных лучей, 4-х краевых $\left(l_{e}\right)$ и 4-х винтовых $\left(l_{s c r}\right)$ луча, в соответствии с элементами скольжения кубических кристаллов: $\{110\}\langle 110\rangle$ (рис. 2).

Краевые лучи формируются благодаря скольжению дислокаций по плоскостям типа $\{110\} 90$, т.е. по плоскостям, которые выходят на исследуемую грань (001) под углом 90, и ориентированы вдоль направлений типа $\langle 110\rangle$. Винтовые лучи образуются благодаря скольжению дислокаций по плоскостям типа $\{110\}_{45}$, выходящих на грань (001) под углом 45 , и направлены вдоль $\langle 100\rangle$.

Длина краевых лучей заметно больше длины винтовых лучей. Форма лучей розеток и распределение плотности дислокаций в них также являются аналогичными. Максимальная плотность дислокаций формируется вблизи отпечатка, которая закономерно уменьшается по

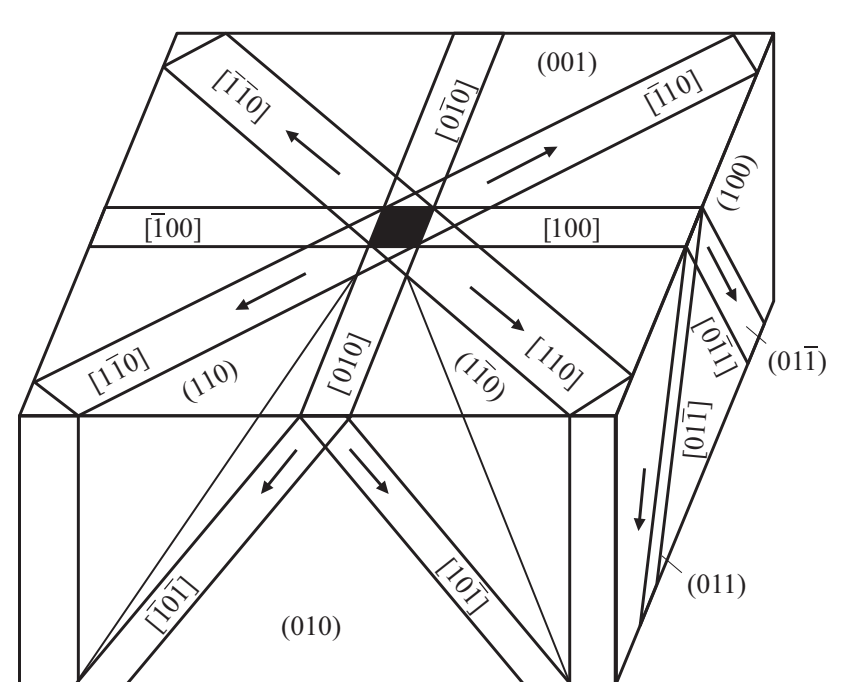

Рис. 2. Схема расположения краевых и винтовых плоскостей скольжения, активных при индентировании грани (001) кубических кристаллов типа $\mathrm{NaCl}$.

мере удаления от места приложения нагрузки. Этот факт свидетельствует о том, что напряжение от индентора постепенно убывает в кристалле по мере удаления от отпечатка, а дислокационная структура образуется в соответствии с геометрией скольжения в кристалле. Деформированная область вокруг отпечатков подчиняется общей закономерности, установленной в работе [6], согласно которой в ней различаются пять основных зон, 
$a$

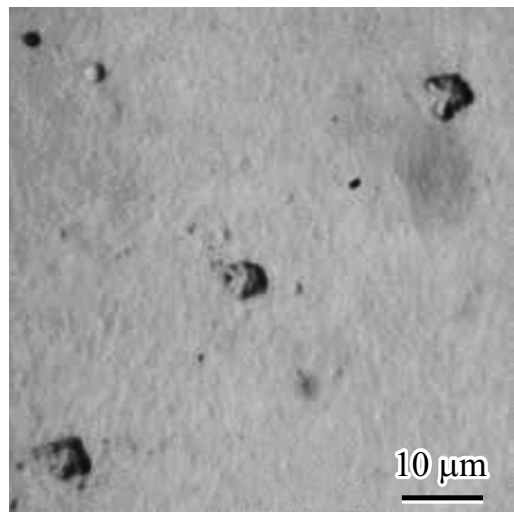

$b$

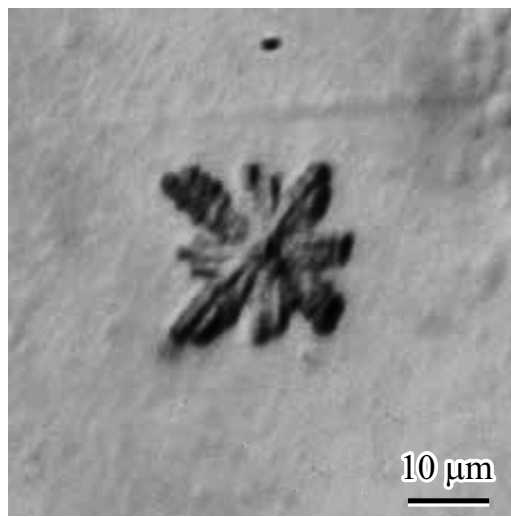

$d$
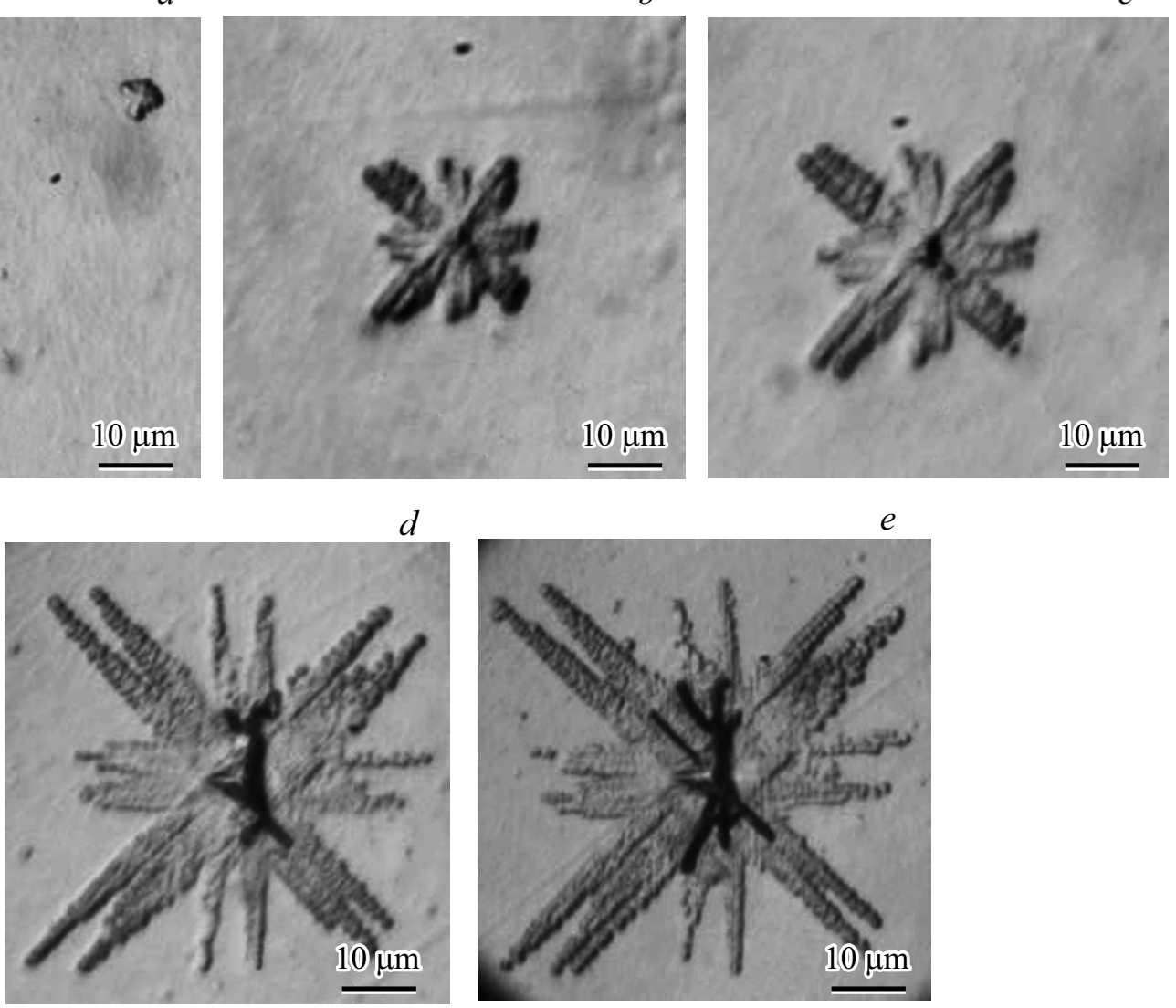

$e$

Рис. 3. $\mathrm{MgO}$, грань (001). Индентор Берковича. Эволюция дислокационных розеток при увеличении нагрузки на индентор. $P$, $\mathrm{mN}$ : $a-4, b-50, c-100, d-700, e-900$.

отмеченных во введении. Некоторые из них хорошо просматриваются на рис. 1.

В то же время анализ вида дислокационных розеток, возникающих вокруг отпечатка Берковича (ДРБ) (рис. $1, e-h)$, указывает на некоторое их отличие от дислокационных розеток, формирующихся вокруг отпечатка Виккерса (ДРВ) (ср. с рис. $1, a-d)$. Так, длина всех четырех краевых лучей у отпечатков Виккерса примерно одинакова. То же самое можно сказать и о длине винтовых лучей. Что же касается отпечатков Берковича, то здесь обнаруживается неожиданное различие. Если винтовые лучи ДРБ расположены симметрично возле отпечатка и, в целом, одинаковы по своей длине и форме, аналогично винтовым лучам ДРВ, то краевые лучи отличаются как по структуре, так и по длине. Три луча имеют примерно одинаковый вид, а четвертый менее развит, является более узким и более коротким. Причем, эффект заметен ярче, когда одна из вершин отпечатка направлена строго по направлению типа $\langle 110\rangle$ (см. рис. $1, e, f)$. Если же одна из вершин отпечатка и перпендикулярная к ней сторона ориентированы строго вдоль $\langle 100\rangle$, в эффекте принимают участие два дислокационных луча (рис. $1, h$ и $3, d$ ), соответственно с меньшим вкладом каждого.
Для выяснения природы наблюдаемого эффекта была изучена эволюция формирования дислокационной розетки при изменении нагрузки на индентор. Было установлено, что эффект наблюдается практически во всем интервале использованных нагрузок. В качестве примера на рис. 3 показана эволюция дислокационных розеток, образованных вокруг отпечатков Берковича в интервале нагрузок $P=(4-900) \mathrm{mN}$ на кристалле $\mathrm{MgO}$.

На начальном этапе внедрения полусферическое закругление вершины индентора сказывается на специфике протекания пластической деформации. По этой причине дислокационные розетки для нагрузки $P=4 \mathrm{mN}$ имеют слегка закругленную форму (рис. $3, a$ ).

С ростом $P$ форма дислокационных розеток последовательно и закономерно меняется, в них начинают просматриваться краевые лучи (вдоль направлений $\langle 110\rangle$ ) и винтовые лучи (вдоль направлений $\langle 100\rangle)$, обусловленные скольжением дислокаций, соответственно, по плоскостям скольжения $\{110\}_{90}$ и $\{110\}_{45}$. Как можно видеть из рис. 3 , при нагрузке $50 \mathrm{mN}$ в соответствии с симметрией грани (001) и активностью элементов скольжения (см. рис. 2), дислокационные розетки уже сформированы из восьми лучей: четыре краевых и четыре винтовых луча. 

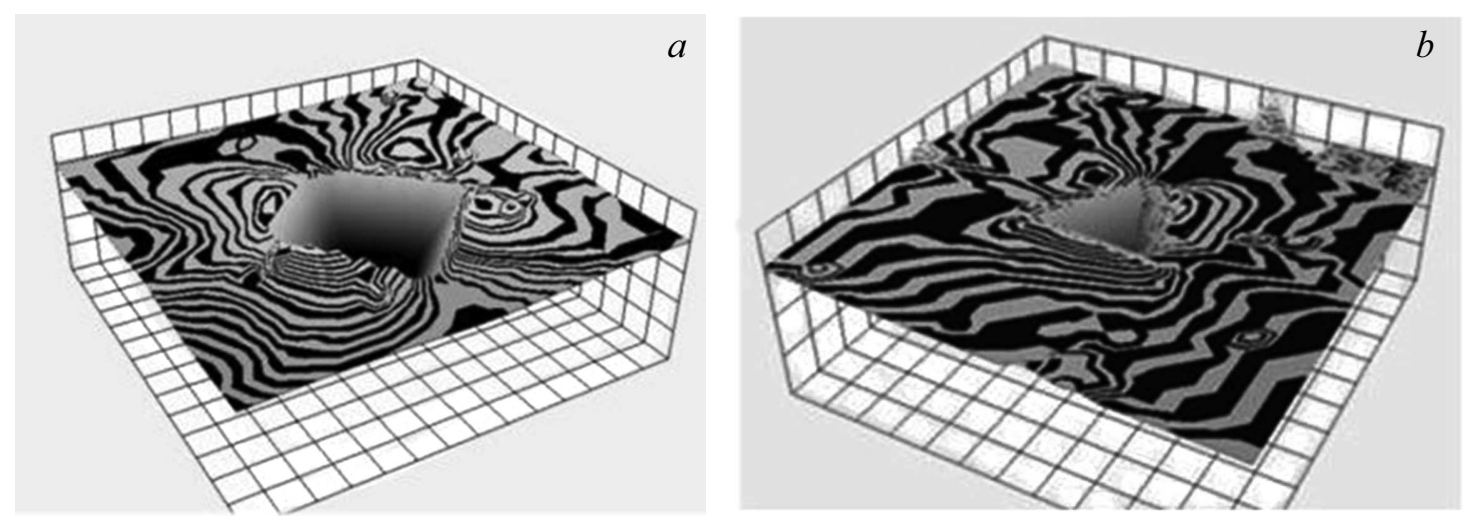

Рис. 4. ACM. Монокристалл $\mathrm{LiF}$, грань (001). Картина рельефа поверхности в режиме 3D вокруг отпечатков, нанесенных инденторами Виккерса и Берковича. $P, \mathrm{mN}: a-200, b-120$. Размер, $\mu \mathrm{m}: a-35 \times 35, b-30 \times 30$.

Одновременно с увеличением размера дислокационных розеток ярче начинает проявляться асимметрия длины краевых лучей розеток, которая имеет место во всех розетках вплоть до максимальных нагрузок (рис. $3, b-e$ ). При этом в интервале $(50-100) \mathrm{mN}$ два луча в левой половине розетки являются более длинными, чем два других луча из правой половины. С дальнейшим ростом нагрузки один их коротких лучей удлиняется, приближаясь по размеру к длинным лучам.

Базируясь на накопленных знаниях $[4,6,10,28]$, можно предположить, что причиной данной аномалии являются три фактора: (i) форма индентора (трехгранная пирамида Берковича), (ii) его ориентация относительно кристаллографических направлений образца, и (iii) специфика расположения активных элементов скольжения кристалла по отношению к граням индентора (см. рис. 2). Рассмотрим сказанное более подробно.

Известно, что при индентировании пирамидальными инденторами деформация неодинакова по различным радиальным направлениям. Наибольшая пластическая деформация наблюдается у середины сторон отпечатков, а наименьшая - по углам отпечатка $[3,4,10]$. Сказанное подтверждается и картиной рельефа поверхности в атомно-силовом микроскопе вокруг отпечатков, нанесенных инденторами Виккерса (рис. 4,a) и Берковича (рис. $4, b$ ).

Отчетливо видно, что около центра всех четырех сторон отпечатка Виккерса возникают холмики вытесненного материала, свидетельствующие о максимальной пластической деформации в этих местах, благодаря дислокационному механизму деформирования. Что же касается отпечатка Берковича, то вокруг него только вблизи центра двух сторон сформированы раздельные холмики. У третьей же стороны другие два холмика объединились в один протяженный менее высокий холмик, что указывает на меньшую степень пластической деформации в этой зоне. Представляется, что причина этого заключается в следующем. В случае индентирования кристаллов $\mathrm{LiF}$ и $\mathrm{MgO}$ индентором Виккерса, когда диагонали отпечатка $d \|\langle 100\rangle$, форма отпечатка соответствует четверной симметрии грани, максимальная деформация имеет место вдоль направлений $\langle 110\rangle$ и совпадает с направлением движения дислокаций в плоскостях скольжения $\{110\}_{90}$, поэтому розетка является симметричной, и краевые лучи примерно равны по своей длине (см. рис. 2).

В отличие от этого, форма пирамиды Берковича не совпадает с симметрией грани, и максимальное тангенциальное напряжение, соответственно, максимальная деформация и вынос материала на поверхность в виде холмиков вблизи отпечатка будет происходить поразному в зависимости от специфики расположения активных элементов скольжения кристалла по отношению к граням индентора.

Так, например, при ориентации одной из сторон отпечатка $A B$ вдоль направления $\langle 110\rangle$ (рис. 5, $a$ ) максимальная деформация будет совпадать с направлением скольжения дислокаций в перпендикулярном к ней дислокационном луче (угол отклонения $\phi_{1}$ между ними будет равен нулю) и зарождающиеся при действии концентрированной нагрузки краевые дислокации будут легко продвигаться вдоль направления $\langle 110\rangle$, формируя максимальный для данной нагрузки краевой луч. Две другие стороны отпечатка $A C$ и $B C$ при этом находятся в менее выгодном положении, они отклоняются от направления легкого скольжения дислокаций на угол $\phi_{2}=30^{\circ}$, тем самым затрудняя движение дислокаций в двух других лучах вдоль направления типа $\langle 110\rangle$, и оказываются короче первого луча. Расположение четвертого краевого луча является самым невыгодным, поскольку в направлении этого луча выходит вершина отпечатка $C$, а как было указано выше, пластическая деформация материала по углам отпечатка наименьшая. В результате этот луч оказывается наименьшей длины, что мы и наблюдаем на эксперименте (см. рис. $1, e-h)$.

Если же повернуть индентор на угол $\phi=15^{\circ}$ (рис. $5, b)$, то расположение его сторон по отношению к элементам скольжения изменится так, что ни у одной из 


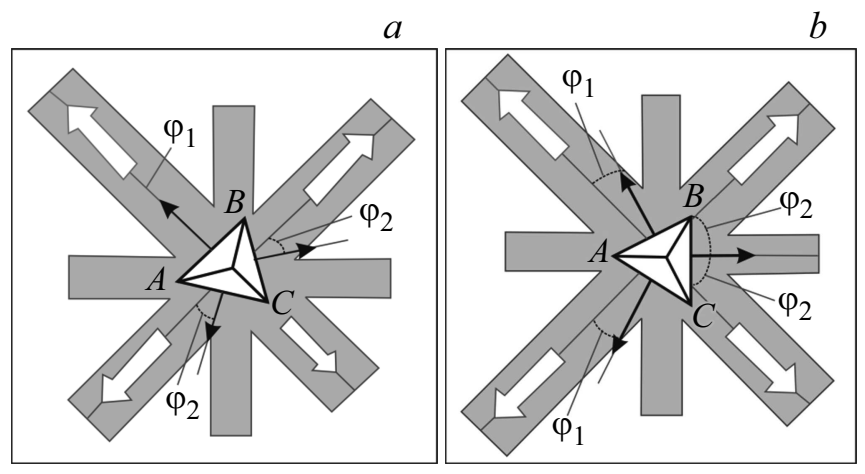

Рис. 5. Схема расположения дислокационных розеток относительно отпечатков. $a-$ сторона $A B$ отпечатка параллельна и перпендикулярна направлениям $\langle 110\rangle, b-$ сторона $B C$ отпечатка параллельна и перпендикулярна направлениям $\langle 100\rangle$. Стрелки белого цвета указывают направление скольжения дислокаций в краевых лучах, стрелки черного цвета показывают направления максимальной пластической деформации у сторон отпечатка

сторон направление максимальной деформации не будет совпадать с направлением скольжения дислокаций (угол $\left.\phi_{1} \neq 0^{\circ}\right)$. В этом случае две стороны отпечатка $A B$ и $A C$ наиболее приближены к направлениям $\langle 110\rangle$. Их отклонение от направления $\langle 110\rangle$ составляет $\phi_{1}=15^{\circ}$, что стимулирует развитие лучей вдоль этих двух направлений. У третьей стороны отпечатка $B C$, параллельной направлению $\langle 100\rangle$, максимальная деформация направлена вдоль $\langle 100\rangle$, отклонение от направления $\langle 110\rangle$ в двух других краевых дислокационных лучах составляет $\phi_{2}=45^{\circ}$, вследствие чего развитие этих лучей ослаблено по сравнению с первыми двумя лучами, и как результат, их длина оказывается короче. Реализация данной картины представлена на рис. 3 .

Приведенный анализ продемонстрировал, с одной стороны, чувствительность дислокационных структур, формирующихся вокруг отпечатков Берковича на кристаллах $\mathrm{LiF}$ и $\mathrm{MgO}$, к форме индентора, с другой стороны выявил наличие ориентационного эффекта, проявляющегося в том, что дислокационная розетка меняет свою форму при повороте индентора относительно кристаллографических направлений образца и его элементов скольжения. Причем, величина эффекта зависит как от ориентации индентора, так и от твердости кристалла. В качестве примера на рис. 6 представлена зависимость длины краевых лучей розеток от величины приложенной нагрузки для кристаллов $\mathrm{LiF}$ и $\mathrm{MgO}$. Отметим, что на данном рисунке представлены результаты измерений длины дислокационных лучей для разных ориентаций индентора: для $\mathrm{LiF}$ - ориентация, соответствующая рис. 5, $b$, для $\mathrm{MgO}$ - ориентация, соответствующая рис. 5,a. Аналогичный ориентационный эффект наблюдался и для двух других ориентаций индентора: для $\mathrm{LiF}$ при ориентации рис. 5, $a$, для $\mathrm{MgO}$ при ориентации рис. $5, b$.

Из рисунка видно, что эффект асимметрии дислокационных розеток зависит от твердости кристалла. Он проявляется ярче на более твердом кристалле $\mathrm{MgO}$, чем на $\mathrm{LiF}\left(H_{\mathrm{MgO}}=8 \mathrm{GPa}, H_{\mathrm{LiF}}=1.1 \mathrm{GPa}\right)$. В соответствии со схемой на рис. $5, b$, на $\mathrm{LiF}$ два длинных луча близки по размерам и объединены на одну кривую, то же касается и двух коротких лучей (рис. 6,a). В отличие от LiF на кристалле $\mathrm{MgO}$ все четыре краевых луча по своим размерам отличаются друг от друга, как показано на рис. $5, a$, и эффект увеличивается с ростом нагрузки на индентор (рис. $6, b$ ).

Другой причиной, приводящей к асимметричной форме дислокационных розеток, является, на наш взгляд, характер напряженного состояния, возникающего в кристалле при действии сосредоточенной нагрузки. Теоретические оценки касательных напряжений, действующих в плоскостях скольжения вдоль направлений скольжения, показали, что при вдавливании индентора в грань (001) кубических кристаллов типа $\mathrm{NaCl}$ создаются более благоприятные условия для развития деформации в глубь кристалла по плоскостям скольжения $\{110\}_{45}$, чем по плоскостям $\{110\}_{90}$ [4,29]. Деформация по плоскостям $\{110\}_{90}$ носит приповерхностный характер
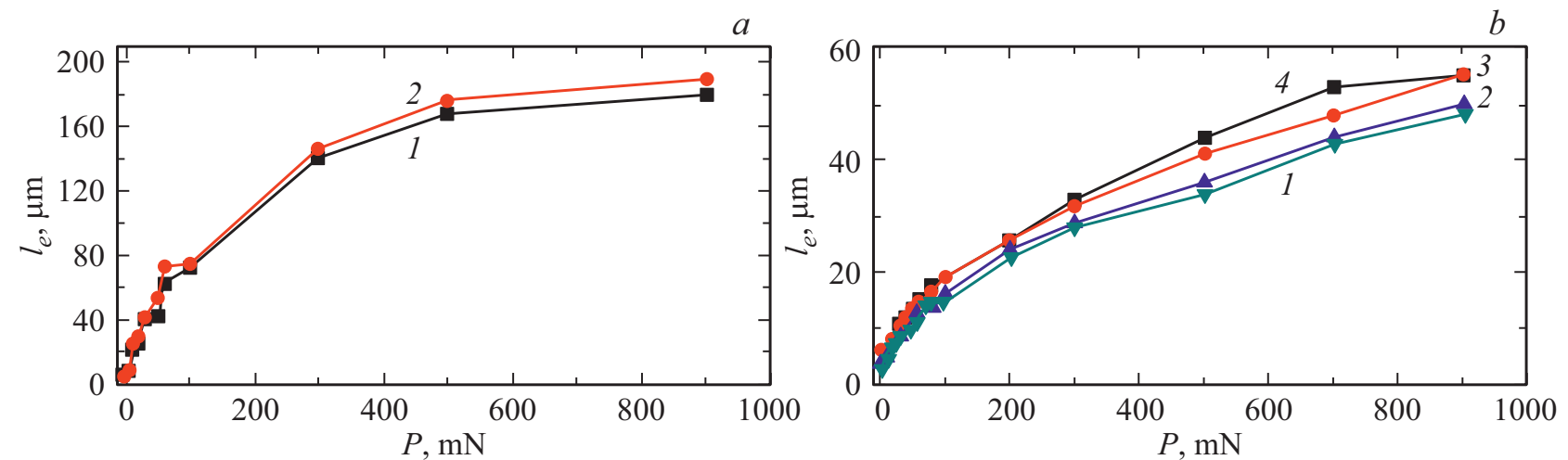

Рис. 6. Зависимость длины краевых лучей $\left(l_{e}\right)$ дислокационных розеток от величины приложенной нагрузки $(P)$. $a-\mathrm{LiF}$, ориентация индентора как на рис. $5, b ; 1-$ короткие лучи, $2-$ длинные лучи, $b-\mathrm{MgO}$, ориентация индентора как на рис. $5, a$; 1, 2, 3, 4 - лучи, расположенные в порядке увеличения длины. 
и примыкает вплотную к индентору. Поэтому краевые лучи дислокационных розеток более чувствительны в форме индентора, чем винтовые. В то же время перенос материала по плоскостям скольжения $\{110\}_{45}$ начинается, главным образом, в зоне под отпечатком и быстро удаляется от него вглубь по расходящимся и сходящимся плоскостям $\{110\}_{45}$, тем самым испытывая меньшее влияние геометрии индентора [4,29].

Следует отметить, что ранее в работе [31] была выявлена зависимость длины лучей дислокационных розеток от ориентации индентора Виккерса на ряде кубических монокристаллов $\mathrm{KCl}, \mathrm{NaCl}$, LiF, MgO. Было установлено, что длина краевых лучей розеток у отпечатков при $d \|\langle 100\rangle$ больше, чем у отпечатков при $d \|\langle 110\rangle$, где $d$ - диагональ отпечатка. Результат согласуется с эффектом, выявленным в настоящей работе при использовании индентора Берковича. Заметим, что для всей серии кристаллов $\mathrm{KCl}, \mathrm{NaCl}, \mathrm{LiF}, \mathrm{MgO}$ винтовые лучи, как и в нашем случае, не испытывали ориентационного эффекта, тем самым подтверждая вышеприведенную интерпретацию.

Так, можно заключить, что обнаруженная в работе чувствительность краевых дислокационных лучей к форме индентора Берковича зависит от нескольких факторов: формы индентора и его ориентации относительно кристаллографических направлений образца и элементов скольжения, подвижности дислокаций в кристалле, его твердости и величины приложенной нагрузки.

\section{4. Заключение}

В работе проведено изучение особенностей формирования дислокационных структур при квазистатическом и инструментальном микро- и наноиндентировании в широком интервале нагрузок $P=(4-900) \mathrm{mN}$ на грани (001) монокристаллов $\mathrm{LiF}$ и $\mathrm{MgO}$. Выявлен эффект чувствительности длины краевых лучей дислокацонных розеток к форме индентора, трехгранной пирамиде Берковича. Показано, что дислокационные розетки, формирующиеся вокруг отпечатков Виккерса, имеют симметричный вид, в то время как розетки вокруг отпечатков Берковича ассимметричны. Краевые лучи дислокационных розеток различаются по своей длине, тогда как винтовые лучи такой асимметрии не демонстрируют. Также обнаружен ориентационный эффект при внедрении индентоа Берковича: $(i)$ один краевой луч из четырех короче остальных трех, когда одна из трех сторон отпечатка расположена вдоль или перпендикулярно направлениям типа $\langle 110\rangle ;$; $(i)$ два луча из четырех короче других двух, когда одна из сторон направлена параллельно и перпендикулярно кристаллографическим направлениям типа $\langle 100\rangle$. Эффект проявляется ярче, когда сторона отпечатка $(a)$ ориентирована параллельно и соответственно перпендикулярно направлениям $\langle 110\rangle$, чем когда $a \|\langle 100\rangle$ и $a \perp\langle 100\rangle$.
Обнаружены еще две закономерности: асимметрия дислокационных розеток проявляется ярче на более твердых кристаллах, обладающих более низкой подвижностью дислокаций, и асимметрия увеличивается с ростом нагрузки на индентор (в пределах использованных в работе нагрузок).

Подводя итог сказанному, можно заключить, что рассмотренные выше факторы, ответственные за аномалию в развитии дислокационных розеток при нано-, микроиндентировании индентором Берковича грани (001) кубических кристаллов, могут быть разделены на две основные группы:

1. Внешние факторы: форма индентора (трехгранная пирамида), ее ориентация, величина приложенной нагрузки и характер напряженного состояния, возникающего в кристалле при действии сосредоточенной нагрузки.

2. Внутренние факторы: тип кристаллической структуры образца, специфика расположения активных элементов скольжения, подвижность дислокаций и, как следствие, величина твердости деформируемого кристалла.

Таким образом, исследования показали, что аномалия дислокационных розеток является эффектом, зависящим от целого ряда факторов, и вклад каждого из них зависит от конкретных условий испытания. Выявленные на примере модельных кристаллов $\mathrm{LiF}$ и $\mathrm{MgO}$ эффекты имеют общий характер и должны приниматься во внимание во время интерпретации экспериментальных данных, получаемых при индентировании как кристаллических, так и некристаллических материалов разного типа.

\section{Финансирование работы}

Настоящая работа выполнена при поддержке Исследовательского проекта Института прикладной физики Республики Молдова (Project № 15.817.02.06A).

\section{Конфликт интересов}

Авторы заявляют, что у них нет конфликта интересов.

\section{Список литературы}

[1] Ю.С. Боярская. Деформирование кристаллов при испытаниях на микротвердость. Штиинца, Кишинев (1972). 235 с.

[2] M.A. Velednitskaya, V.N. Roshanskii, L.F. Comolova, G.V. Saparin, J. Schreiber, O. Brummer. Phys. Status Solidi A 32, 123 (1975).

[3] В.К. Григорович. Твердость и микротвердость металлов. Наука, М. (1976). 232 с.

[4] Ю.С. Боярская, Д.З. Грабко, М.С. Кац. Физика процессов микроиндентирования. Штиинца, Кишинев (1986). 294 с.

[5] V. Domnich, Y. Gogotsi. Rev. Adv. Mater. Sci. 3, 1 (2002).

[6] D. Grabco, B. Pushcash, M. Dyntu, O. Shikimaka. Phil. Mag. A 82, 10, 2207 (2002). 
[7] M.M. Chaudhri. Dislocations and Indentations. Chapter 70 / Ed. F.R.N. Nabarro, J.P. Hirth. Cavewnsish Laboratory, UK (2004). $450 \mathrm{p}$.

[8] I. Manika, J. Maniks. Acta Mater. 54, 2049 (2006).

[9] Ю.И. Головин. ФТТ 50, 2113 (2008).

[10] D. Grabco, O. Shikimaka, E. Harea. J. Phys. D 41, 074016 (2008).

[11] Материалы 51-й Междунар. конф. „Актуальные проблемы прочности“. Харьков, Украина. ННЦ ХФТИ (2011). 430 с.

[12] Sh. Nath, A. Dey, A.K. Mukhopadhyay, B. Basu. MSEA. 513514, 197 (2009).

[13] C.A. Schun. Mater. Today 9, 5, 32 (2006).

[14] Y. Gao, S.M. Allamah, D. Nankivil, T.S. Satharaj, T. Otiti, W.O. Soboyejo. MSEA A 427, 232 (2006).

[15] A.A. Volinsky, W.W. Gerberich. Microelectron. Eng. 69, 519 (2003).

[16] T.-Y. Zhang, W.-H. Xu, M.H. Zhao. Acta Mater. 52, 57 (2004). DOI: 10.1016/j.actamat.2003.08.026

[17] W.C Oliver, G.M. Pharr. J. Mater. Res. 19, 1, 3 (2004).

[18] И.В. Гончарова. Определение методом индентирования физико-механических свойств материалов с разной кристаллической структурой. Дис. канд. физ.-мат. наук, Киев (2017). $171 \mathrm{c}$.

[19] С.Н. Дуб, В.В. Бражкин, В.А. Белоус, Г.Н. Толмачева, П.В. Коневский. Сверхтвердые материалы 4, 3 (2014).

[20] Y.Y. Lim, M.M. Chaudhri. Phil. Mag. A 79, 12, 2979 (1999).

[21] Y.-J. Chiu, Sh.-R. Jian, T.-J. Liu, P.H. Le, J.-Y. Juang. Micromachines 9, 611 (2018). doi:10.3390/mi9120611

[22] A. Kosinova, R. Schwaiger, L. Klinger, E. Rabkin. Beilstein J. Nanotechnol. 7, 2088 (2016).

[23] Sh.-R. Jian, J.-Y. Juang. J. Nanomater. 2012, 1 (2012). DOI: $10.1155 / 2012 / 914184$

[24] F. Javaid, E. Bruder, K. Durst, A. Stukowski. Acta Mater. 139, 1 (2017). doi.org/10.1016/j.actamat.2017.07.055Get rights and content

[25] S. Chattoraj, L. Shi, M. Chen, A. Alhalaweh, S. Velaga, Ch.C. Sun. Cryst. Growth Des. 14, 3864 (2014). dx.doi.org/10.1021/cg500388s

[26] K. Geng, F. Yang, Th. Druffel, E.A. Grulke. Polymer 46, 11768 (2005).

[27] D.Z. Grabco, O.A. Shikimaka, M. Elisa, B.A. Sava, L. Boroica, C. Pyrtsak, A. Prisacaru, Z. Danitsa, I. Feraru, D. Ursu. Surf. Eng. Appl. Electrochem. 48, 4, 365 (2012).

[28] D. Grabco. Mold. J. Phys. Sci. 1, 3, 94 (2002).

[29] Yu.S. Boyarskaya, D.Z. Grabko. Kristal Technik. 8, 12, 1367 (1973).

[30] D. Grabco, D. Leu. MSEA 527, 6987 (2010).

[31] Ю.С. Боярская, Д.3. Грабко, Д.С. Пишкова, С.С. Шутова. В сб. Деформирование кристаллов при действии сосредоточенной нагрузки / Под ред. С.Г. Симашко. Штиинца, Кишинев 68 (1978). 127 с.

[32] D. Kiener, K. Durst, M. Rester, A.M. Minor. JOM 61, 3, 14 (2009).

Редактор Ю.Э. Китаев 